This item was submitted to Loughborough's Research Repository by the author.

Items in Figshare are protected by copyright, with all rights reserved, unless otherwise indicated.

\title{
Influence of the variable valve timing strategy on the control of a homogeneous charge compression $(\mathrm{HCCl})$ engine
}

PLEASE CITE THE PUBLISHED VERSION

http://www.sae.org/events/sfl/highlights.htm

PUBLISHER

(C) SAE International

VERSION

VoR (Version of Record)

LICENCE

CC BY-NC-ND 4.0

REPOSITORY RECORD

Milovanovic, Nesa, Rui Chen, and J.W.G. Turner. 2011. "Influence of the Variable Valve Timing Strategy on the Control of a Homogeneous Charge Compression ( $\mathrm{HCCl})$ Engine". figshare.

https://hdl.handle.net/2134/8405. 
This item was submitted to Loughborough's Institutional Repository (https://dspace.lboro.ac.uk/) by the author and is made available under the following Creative Commons Licence conditions.

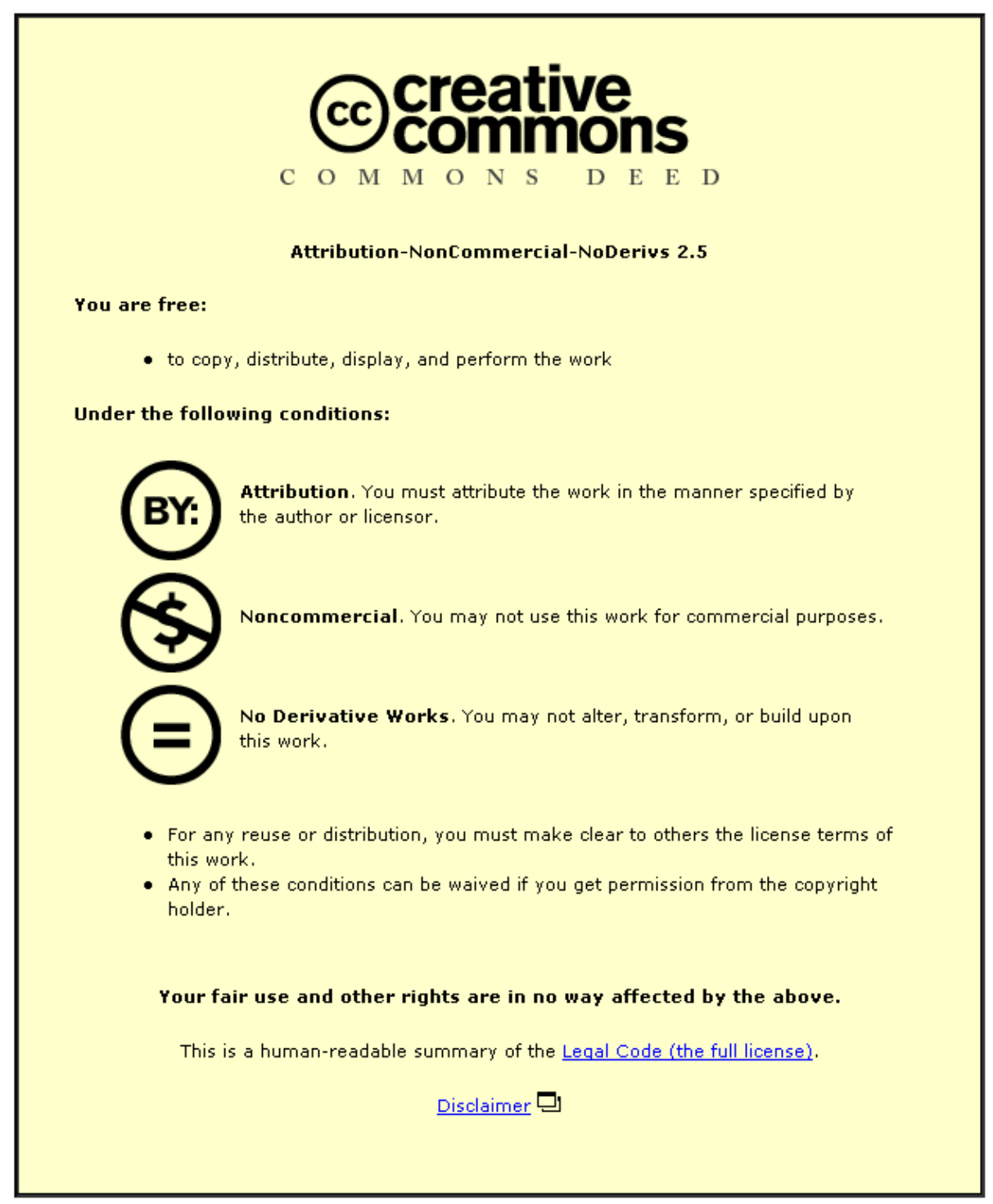

For the full text of this licence, please go to: http://creativecommons.org/licenses/by-nc-nd/2.5/ 


\title{
Influence of the Variable Valve Timing Strategy on the Control of a Homogeneous Charge Compression ( $\mathrm{HCCl}$ ) Engine
}

\author{
Nebojsa Milovanovic and Rui Chen \\ Department of Aeronautical and Automotive Engineering, Loughborough University \\ Jamie Turner \\ Powertrain Research Department, Lotus Engineering
}

Reprinted From: Homogeneous Charge Compression Ignition $(\mathrm{HCCl})$ 
All rights reserved. No part of this publication may be reproduced, stored in a retrieval system, or transmitted, in any form or by any means, electronic, mechanical, photocopying, recording, or otherwise, without the prior written permission of SAE.

For permission and licensing requests contact:

SAE Permissions
400 Commonwealth Drive
Warrendale, PA 15096-0001-USA
Email: permissions @ sae.org
Fax: $\quad 724-772-4891$
Tel: $\quad 724-772-4028$

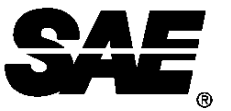

Global Mobility Database ${ }^{\circledast}$

All SAE papers, standards, and selected

books are abstracted and indexed in the

Global Mobility Database.

For multiple print copies contact:

SAE Customer Service

Tel: $\quad$ 877-606-7323 (inside USA and Canada)

Tel: $\quad$ 724-776-4970 (outside USA)

Fax: $\quad$ 724-776-1615

Email: CustomerService@sae.org

\section{ISBN 0-7680-1319-4}

\section{Copyright $\odot 2004$ SAE International}

Positions and opinions advanced in this paper are those of the author(s) and not necessarily those of SAE. The author is solely responsible for the content of the paper. A process is available by which discussions will be printed with the paper if it is published in SAE Transactions.

Persons wishing to submit papers to be considered for presentation or publication by SAE should send the manuscript or a 300 word abstract of a proposed manuscript to: Secretary, Engineering Meetings Board, SAE.

\section{Printed in USA}




\title{
Influence of the Variable Valve Timing Strategy on the Control of a Homogeneous Charge Compression ( $\mathrm{HCCl}$ ) Engine
}

\author{
Nebojsa Milovanovic* and Rui Chen \\ Department of Aeronautical and Automotive Engineering, Loughborough University \\ Jamie Turner \\ Powertrain Research Department, Lotus Engineering
}

Copyright ( 2004 SAE International

\begin{abstract}
Homogeneous Charge Compression Ignition (HCCI) engine concept has the potential to be high efficient and to produce low NOx and particulate matter emissions. However, the problem of controlling the combustion over the entire load/speed range limits its practical application. The HCCI combustion is controlled by chemical kinetics of the charge mixture, with no influence of the flame diffusion or turbulent propagation. Therefore, to achieve a successful control of the HCCI process, the composition, temperature and pressure of the charge mixture at IVC point have to be controlled. The use of the variable valve timing strategy that enables quick changes in the amount of trapped hot exhaust gases shows the potential for the control of the HCCI combustion.
\end{abstract}

The aim of this paper is to analyse influence of the variable valve timing strategy on the gas exchange process, the process between the first valve open event (EVO) and the last valve closing event (IVC), in a HCCI engine fuelled with standard gasoline fuel $(95 \mathrm{RON})$. The gas exchange process affects the engine parameters and charge properties and therefore plays a crucial role in determining the control of the HCCI process.

Analysis is performed by the experimental and modelling approaches. The single-cylinder research engine equipped with the fully variable valve train (FVVT) system was used for the experimental study. A combined code consisting of a detailed chemical kinetics code and one-dimensional fluid dynamics code was used for the modelling study.

The results obtained indicate that the variable valve timing strategy has a strong influence on the gas exchange process, which in turn influences the engine parameters and the cylinder charge properties, hence the control of the HCCI process. The EVC timing has the strongest effect followed by the IVO timing, while the EVO and IVC timings have the minor effects.

Keywords: HCCI, Control, Variable Valve Timing, Gas Exchange Process, Trapped residual gas, Gasoline.

${ }^{*}$ Corresponding author.

\section{INTRODUCTION}

The Controlled Auto Ignition (HCCI) combustion is a process that combines features of the SI and CI processes. In a HCCI engine the air and fuel are premixed homogeneously prior to ignition and then ignited by the compression from the piston motion. The ignition is provided in multiple points and therefore the charge gives a parallel energy release. This results in the uniform and simultaneous auto-ignition and chemical reaction throughout the whole charge without flame propagation. In the HCCI combustion chemical kinetics of air-fuel mixture plays the crucial role with no requirements for the turbulence and mixing ${ }^{1}$.

The HCCI combustion was initially recognised at the twostroke engines in late 1970's by Onishi et al [1] and Noguchi et al [6]. They observed that the premixed air-fuel mixture ignites simultaneously at many points without obvious flame propagation. The notion that the HCCI combustion is dominated by chemical kinetics of employed air-fuel mixture has been supported by recent spectroscopic and imaging investigations $[2,3]$. The results obtained indicate that the ignition occurs simultaneously in multiply points with no flame propagation.

The HCCI engine offers benefit in comparison to the spark ignited and compression ignited engines in higher efficiency due to elimination of throttling losses at part and idle loads. There is a possibility to use high compression ratios since it is not knock limited, and in significant lower $N O_{x}$ and particulate matter emissions due to much lower combustion temperature and elimination of fuel rich zones.

The disadvantages of the HCCI engine are relatively high hydrocarbon and carbon monoxide emissions at low loads, high peak pressures and rates of heat releases at high loads, reduced engine speed range and power per displacement and difficulties in the starting and controlling the engine. Some of these advantages may be reduced or eliminated by operating the HCCI engine in a 'hybrid mode', or by using different types of catalysators. However, there are some problems

\footnotetext{
${ }^{1}$ There are currently divided opinions among scientific society regarding regarding the role of turbulence in HCCI combustion. It is generally agreed that the onset of HCCI combustion is controlled by local chemical kinetic reaction rates, with no requirement for flame propagation $[1,2,3]$. However, the influence of turbulence cannot be neglected as it may have an indirect effect by affecting the temperature distribution and the boundary layer thickness within the cylinder $[4,5]$.
} 
regarding the controlling of a HCCI engine over the entire load/speed range that keep the HCCI out of commercial use.

The control of HCCI combustion consists of two aspects: the control of ignition timing to occur in the vicinity of the top dead centre (TDC) and the control of heat release rate (combustion speed) at high loads to prevent excessive noise and engine damage. The HCCI ignition is determined by the charge mixture temperature and composition and to a smaller extent pressure. In this way, the HCCI combustion is achieved by controlling the charge mixture temperature, composition and pressure (i.e. charge mixture properties) at the beginning of the compression stroke (IVC point). As the HCCI combustion is kinetically controlled it means that the rate of heat release depends on correct combustion phasing and is closely linked with the ignition delay. Therefore, the successful control strategy has to be able to control the charge mixture properties at the IVC point over the entire load/speed range.

Different methods that have the potential to control the start of auto ignition and the heat release rate of the HCCI combustion, together with their effectiveness and practical feasibility, have been discussed in [7]. Trapping the hot residual gases (RG) into the cylinder, accomplished by fully variable valve timing (FVVT) system, appears to be the most promising and the most feasible way for achieving the HCCI combustion control in the certain load range [8] ${ }^{2}$. The FVVT system allows quick changes in the cylinder charge temperature and composition by retaining the hot exhaust gases from previous cycles. By varying the amount of trapped residual gases the temperature and composition of the charge mixture can be adjusted.

The aim of this paper is to analyse influence of the variable valve timing strategy on the gas exchange process (GEP) in a HCCI engine fuelled with standard gasoline fuel (95RON). The GEP takes place between the first valve open event (EVO) and the last valve closing event (IVC). Since GEP precedes the compression stroke, where the auto-ignition and heat release rate processes occur, it influences the engine parameters and charge mixture properties, hence the control of the HCCI combustion.

Analysis is performed by the experimental and modelling approaches. The single-cylinder research engine equipped with the fully variable valve train (FVVT) system was used for the experimental study. A combined code consisting of a detailed chemical kinetics code and one-dimensional fluid dynamics code was used for the modelling study.

The effects of the variable valve timing strategy on the engine parameters (such as the trapped RG rate, load, pumping losses, volumetric efficiency and trapped gas temperature) and cylinder charge properties (such as composition, temperature and pressure) were investigated. The results obtained were presented and analysed.

\section{EXPERIMENTAL APPARATUS AND SET-UP}

\footnotetext{
${ }^{2}$ Trapping of residual gases with FVVT system has so far been applied mostly on 'hybrid' SI/HCCI engines.
}

ENGINE - The engine employed in this research is a single cylinder, 4-stroke research engine based on the GM family one-1.8 litre series architecture. The photograph of the engine is shown in Figure 1.

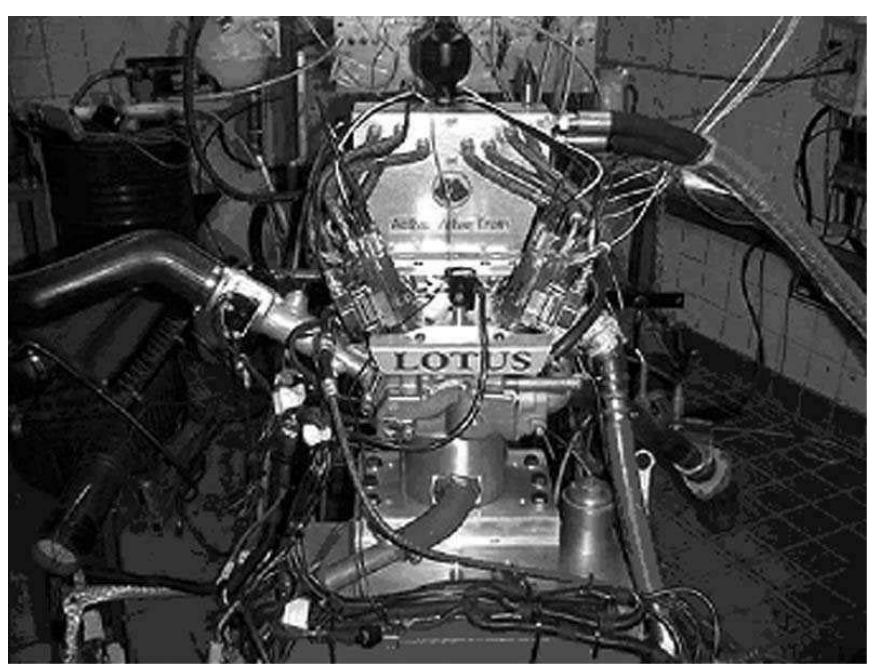

Figure 1: Single-cylinder research engine with Lotus AVT System.

It consists of a production piston, connecting rod and stroke, with a standard 4-cylinder head on top of a water cooled barrel to join the family one part to the custom made bottom end. Only the front cylinder of the head is operational. The water jacket uses a combination of machined modifications and brackets. Unnecessary water transfer ports are blanked off. The engine has a bespoke single cylinder bottom end designed and developed by Lotus to allow either pure combustion work or optical access versions to be built. The exhaust system used on the single cylinder research engine was a standard one. The system was not modified since the exhaust gases were trapped into cylinder by using the early exhaust valve closure event coupled with the late inlet valve opening event. In that way a major amount of the available RG was trapped inside cylinder (up to 80\%) and a rest was discharged through the exhaust system.

The major engine specifications and tests conditions are shown in Table 1 (Refer to Appendix). The detail description of the engine can be found in [8].

The research FVVT system is fitted to allow the variable valve timing strategy to be used to trap the pre-defined quantity of RG. The open and closing timings of the each of four electro-hydraulically driven valves are independently variables and can be digitally controlled. Valve opening profiles can be selected and entered into the software by the user. The control software uses inputs from a crankcase encoder and valve linear displacement transducers to facilitate a closed-loop control to satisfy a 'desired versus actual' position control until the required profiles are achieved. Fine tuning of valve profiles is accomplished by using valve-specific gain controllers.

The compression ratio can be easily changed in this engine, due to the separate barrel and, more importantly due to the FVVT system, which rules out the need for modification of the belt runs and other parts. The bottom end can accept various strokes up to and including $100 \mathrm{~mm}$, and is capable 
of running up to $5000 \mathrm{rpm}$ (depending on stroke).

The engine was connected to a Froude AG30, 30KW eddycurrent dynamometer. A redline ACAP data acquisition system from DSP Technologies Inc. is used together with Horiba MEXA 7100 DEGR emissions analyzer. The fuel was port injected and the engine management system was a conventional Lotus V8 controller.

VALVE EVENTS FOR HCCI COMBUSTION - The technique used to initiate and to control the HCCI combustion relies on the trapping of a pre-determined quantity of RG by closing the exhaust valves relatively early in the exhaust stroke and by opening the inlet valves relatively late in the intake stroke. The general principle can be seen in Figure 2.
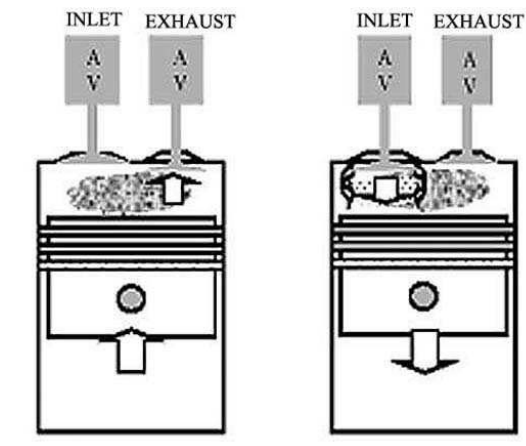

\begin{tabular}{|l|}
\hline Key: \\
EVC-exhaust \\
valve closing \\
IVO-inlet \\
valve opening \\
\hline
\end{tabular}

Exhaust Stroke-Early EVC Induction Stroke-Late IVO

Figure 2: The sequential valve event strategy

The trapped RG are then compressed during the final stage of the exhaust stroke. As the piston descends on the intake stroke, the inlet valves are opened and a fresh charge is drawn into the cylinder which is partially filled with exhaust gases. At the end of the intake stroke the inlet valves are closed and the mixture of a fresh charge and residual gas is then compressed in the next compression stroke. The HCCI combustion occurs as the mixture temperature increases in the final stage of the compression stroke. Once the HCCI has occurred, the power stroke drives the piston down and the cycle is thus repeated. This method is named a sequential method. One more method for achieving HCCI combustion, the simultaneous method, has also been derived. Generally, in this method, as the piston reaches BDC from the power stroke, the exhaust valves are opened and all of the exhaust gases are expelled from the cylinder. As the piston passes TDC, on the induction stroke, both inlet and exhaust valves are opened simultaneously and fresh charge and exhaust gas are together drawn into the cylinder. Again, the HCCI combustion occurs as the mixture temperature increases in the final stage of the compression stroke. Once HCCI has occurred, the power stroke drives the piston down and the cycle is thus repeated. Detail explanations of these two methods can be found in $[8,9]$.

In order to trap the various quantities of $\mathrm{RG}$ and to obtain transition from the conventional SI combustion to HCCI combustion series of valve timings are used. Figure 3 summaries the valve timings and estimated quantities of the trapped TRG.

Transition from SI to HCCI mode is achieved by increasing the negative valve overlap between the exhaust valve closure

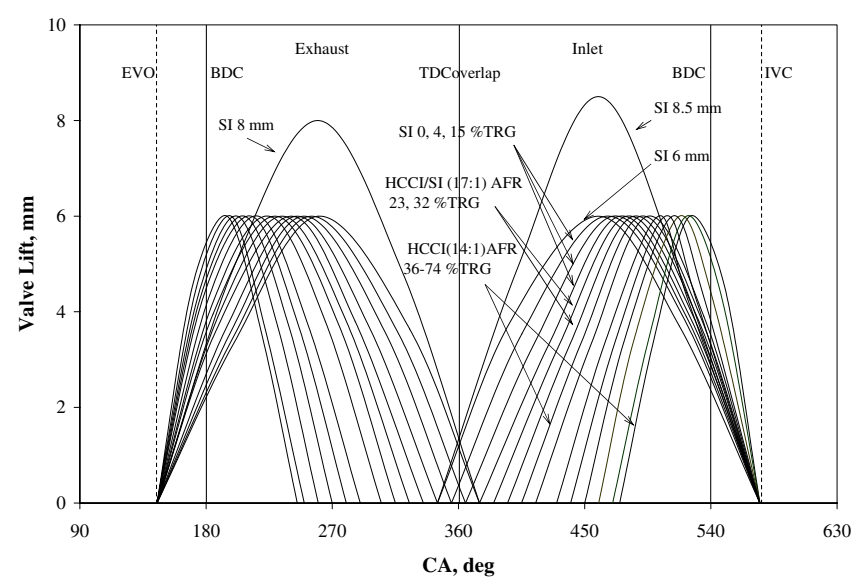

Figure 3: Conventional valve profiles for the SI combustion and profiles suitable for the HCCI combustion

event (EVC) and inlet valve opening event (IVO) and by reducing the valve lift. The intake and exhaust valve events are varied from a 'normal' valve events with positive valve overlap (as for a typical 4-stroke SI engine), to a very early EVC coupled to a symmetrically very late IVO. With the increase of the negative valve overlap, a camless HCCI engine goes from the conventional SI operation, through a transient period, and into the HCCI operation $[8,10]$. The valve lifts of $8 \mathrm{~mm}$ for the exhaust valves and $8.5 \mathrm{~mm}$ for the inlet valves are used for the SI mode. When the engine is operated in a transient and the HCCI mode, the valve lift is reduced to $6 \mathrm{~mm}$ for all valves (exhaust and intake). The reduction in valve lift is applied to reduce the valve dynamic loading to an acceptable level.

The EVC is varied from $245^{0} \mathrm{CA}$ to $375^{0} \mathrm{CA}$ absolute scale ${ }^{3}$, as it is shown in Figure 3.

The EVO is varied symmetrically relative to $\mathrm{TDC}_{\text {overlap }}{ }^{4}$. When the distance from EVC to the $\mathrm{TDC}_{\text {overlap }}$ is equal to the distance from $\mathrm{TDC}_{\text {overlap }}$ to the IVO measured in degrees $\mathrm{CA}$, the valve overlap, positive or negative, is symmetrical. When the valve overlap is symmetrical, the cylinder pressure at the IVO is approximately the same as that at the EVC. This allows maximum recovery of the available compression work with the minimum reverse flow of exhaust gases into the intake manifold $[9,10,11]$.

The EVO and IVC timings are kept constant at $145^{\circ} \mathrm{CA}$ and $575^{\circ} \mathrm{CA}$ respectively ${ }^{5}$. Other engine parameters such as the compression ratio, engine speed, intake temperature and equivalence air-fuel ratio are kept constant at values specified in Table 1 (Refer to Appendix).

\section{SIMULATION MODEL}

The simulation of the HCCI engine is carried out by combining the Aurora detail chemical kinetics code from

\footnotetext{
${ }^{3}$ The absolute scale has $0^{0} \mathrm{CA}$ when the piston is in the TDC of the combustion cycle $\left(\mathrm{TDC}_{\text {comb }}\right)$.

${ }^{4} \mathrm{TDC}_{\text {overlap }}$ is when the piston is in the TDC of the expansion cycle or $360^{\circ} \mathrm{CA}$.

${ }^{5} \mathrm{EVO}$ is chosen to be at $145^{0}$, so the blowdown process can assist in expelling the exhaust gases. The IVC timing of $575^{\circ}$ is chosen to take advantage of the ram effect at high speeds.
} 
the Chemkin III combustion package [12] with the onedimensional fluid-dynamic Lotus Engine Simulation (LES) code [13].

The Aurora code considers the engine chamber as a singlezone reactor with a variable volume. The volume is varied with time according to the slider-crank relationship. The mixture of fuel, air and exhaust gases is assumed to be homogeneous with even spatial distribution of mixture composition and thermodynamic properties. The heat loss is calculated by using Woschni's heat transfer correlation with a temperature difference between the average gas temperature and the time averaged wall temperature [14]. The radiation and conduction heat losses to the engine chamber walls, blowby and crevices are not considered.

The LES is one-dimensional fluid-dynamic engine simulation code capable of predicting the complete performance of an engine system [13]. The program can be used to calculate:

- The full and part load performance of the engine under steady-state and transient operations.

- The in-cylinder heat transfer data.

- The instantaneous gas property variations within the engine manifolds.

- Turbocharger and supercharger matching conditions.

In the LES code, the flow in the pipes is solved using onedimensional model of pipe gas dynamics. The conditions within pipe elements are calculated at each time step by solving a set of conservation equations for mass, momentum and energy. The equations assume that the gas flow uniformly files the entire pipe. A shock-capturing finite volume scheme is used to solve the governing equations of gas flow in pipes.

The numerical method used is based on the two-step LaxWendroff scheme, used in conjunction with a symmetric nonlinear flux limiter, giving second-order spatial and temporal accuracy. This scheme is a member of the class of shockcapturing finite difference schemes that are capable of handling shock waves and super-sonic flows that occur in the manifolds of high-performance engines. The flux limiter, which is based on the total variation diminishing criterion, helps to prevent the occurrence of spurious oscillations in the solution when shock waves and contact discontinuities are encountered [13] .

The LES program allows the user to build a model of the entire engine by selecting engine components from a toolbox and connecting them by pipe elements.

The simulation is started with the Aurora code which calculates the compression (from IVC), auto-ignition, combustion and expansion (until EVO), with the time step of $1^{0}$ crank angle. The initial values of the charge mixture at the IVC point, such as temperature, pressure and composition are assumed. At the end of expansion stroke the calculated data of the cylinder pressure, temperature and exhaust gas composition are transferred to the LES code, which uses those as an input. LES code performers the calculation of the exhaust and intake strokes (from EVO to IVC point-gas exchange process), with the same time step as the Aurora code. The data for the charge mixture temperature, pressure and composition obtained at the end of intake strokes (IVC point) are transferred back to the Aurora code and use as an input for the new calculation cycle. The calculation continues until differences between runs reach the convergence criteria.

Aurora is chosen due to its ability to predict accurately autoignition of the HCCI combustion $[15,16,17]$, whilst the LES code is employed due to its ability to model the instantaneous charge mixture properties in the engine manifolds.

\section{MODEL VALIDATION}

The results obtained by using the simulation model are validated against the experimental results. It was founded that at least 30 cycles have to be calculated to reach a satisfactory degree of convergence with the experimental results. The engine specification and conditions used in the simulation were the same as those used in the experiment and summarised in Table 1 ( $\epsilon$ 10.5, engine speed 2000 rpm, bore $x$ stroke 80.5 $x 88.2 \mathrm{~mm}, 50 \%$ TRG, gasoline fuel (95RON) and stoichiometric equivalence air-fuel ratio). The charge mixture pressure, temperature and composition at the IVC point were assumed or estimated. The charge pressure was assumed to be 1 bar (naturally aspirated engine). The charge temperature and composition were estimated from the amount of trapped exhaust gases obtained from the test and by assuming the mixing of the ideal gases. The detailed procedure has been reported in $[11,18,19]$. It is very important to be able to estimate correctly the charge properties at IVC, since it is crucial for the accurate modelling of the ignition of HCCI process. The charge values at IVC are instantaneous ones and therefore difficult to measure accurately. These values greatly depend on the flow-dynamic and gas exchange processes that take place from the EVO to IVC.

For the simulation of gasoline fuel $95 \mathrm{RON}$, a mixture of isooctane and n-heptane fuels (95\% of iso-octane and $5 \%$ of n-heptane by volume) is used. The detailed chemical kinetic mechanism for a mixture of iso-octane and n-heptane fuel, which consists of 1087 species and 4392 reactions with complete $\mathrm{NO}_{x}$ chemistry, has been developed in-house and validated successfully against the available test data. The mechanism is able to predict auto-ignition behaviour for various fuel research octane numbers (RON) at different temperatures and pressures and it is explained in detail in [20]. The cylinder wall, piston and head are all assumed to be at the uniform temperature of $500 \mathrm{~K}$.

The calculated cylinder pressure history is compared to the cylinder pressure history recorded in the test and results are presented in Figure 4.

It can be seen that the general shape of the experimental cylinder pressure curve is well reproduced over the complete cycle. The peak cylinder pressure is over predicted due to assumptions that whole cylinder charge burns simultaneously and completely and due to the deficiency of the single-zone assumption to model temperature gradient within the charge mixture. In a real engine, the charge mixture inside the cylinder is not uniform in temperature and composition and a small portion of fuel captured in crevices will not burn. Therefore, the pressure gradient after ignition will be lower. On the other hand the start of auto-ignition is predicted correctly. The pressure pulses (pressure waves generated by the blowdown and displacement processes) predicted by the LES 


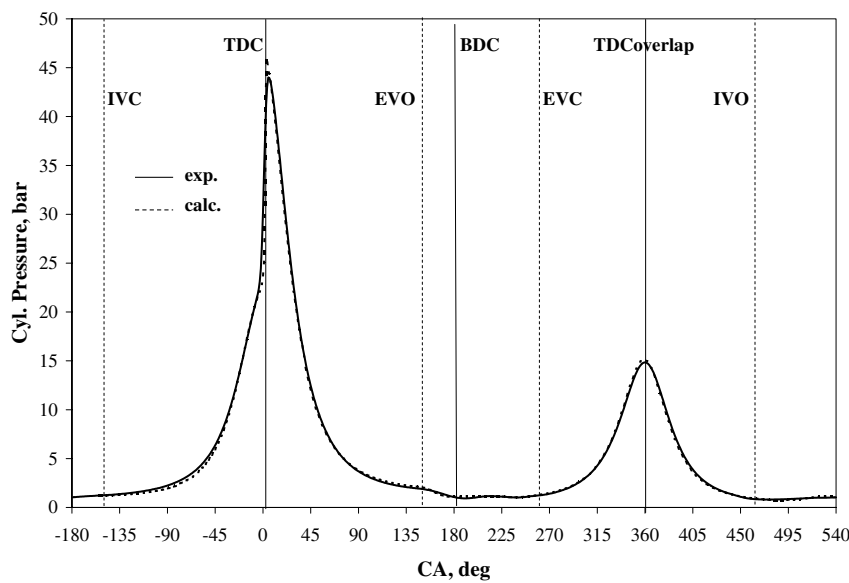

Figure 4: Comparison of calculated and experimental values

code, at the start of the gas exchange process (EVO point), are also consistent with the measured ones. The comparison of the calculated and experimental values for several global engine parameters is shown in Table 2 (Refer to Appendix).

It can be seen that experimental values are generally well matched within a difference of $10 \%$. The values of the engine parameters such as IMEP, BMEP, Indicated Power, Volumetric Efficiency, Mechanical Efficiency and BSFC are over-predicted. IMEP, BMEP and Indicated Power are overpredicted because model over-predicts the peak cylinder pressure and the pressure gradient after ignition (a consequence of single-zone approach) and the gas exchange losses. As a result of IMEP and BMEP over-prediction the simulated Mechanical Efficiency is over-predicted too. The over-prediction of BSFC is highly likely result of an over-prediction of a Volumetric Efficiency that results in a higher amount of air and fuel into the charge. More fuel gives higher load, whilst the faster combustion (a consequence of assumptions that the whole charge burns simultaneously and completely) gives a higher heat losses resulting in over-prediction of the BSFC.

The temperature in the exhaust manifold is matched within a difference of $1.1 \%$ while the difference for the quantity of trapped TRG is within $4 \%$. It is worth emphasing that the quantity of trapped $R G$ in the experiment was estimated since it could not be measured. The range of the differences for the calculated engine parameters seems acceptable considering that the accuracy of the experimental data is not exactly known. Usually with a pressure transducer suited for a thermodynamic evaluation, IMEP can be determined with less than $3 \%$ difference, but sometimes this can be up to $10 \%$ $[11]^{6}$.

An additional validation of the simulation model is carried out for all other points where the HCCI operational mode was achieved. These points are for 32, 36, 41, 45, 55 and $59 \%$ TRG. Comparison of the measured values for the exhaust gas temperature- $\mathrm{T}_{\text {exh }}$ (measured in the exhaust manifold) with calculated ones is shown in Figure 5, comparison of the IMEP and BMEP measured and calculated values in Figure 6, and comparison of the BSFC values in Figure 7.

It can be seen that the trends of the experimental results

\footnotetext{
${ }^{6}$ According to the manufacture of the pressure transducer, sometimes the measured values for IMEP (pressure) can be affected by a thermal shock.
}

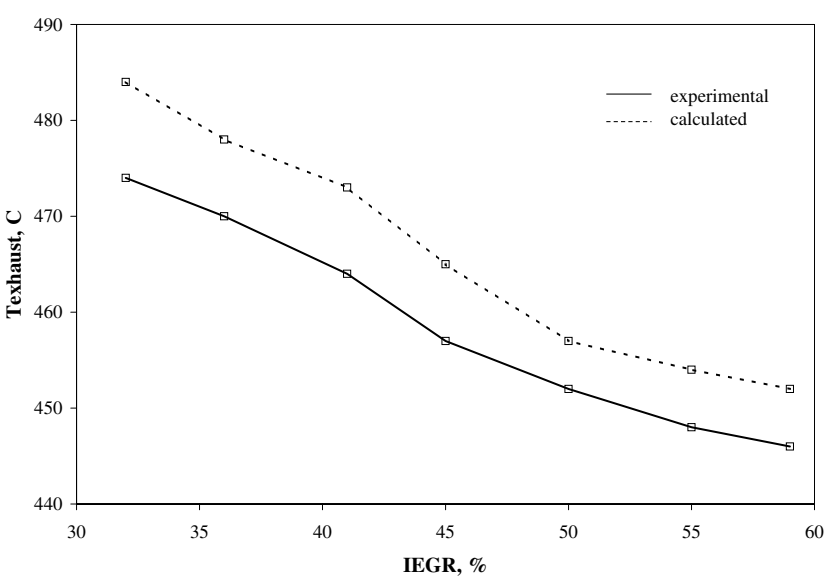

Figure 5: Comparison of calculated and experimental values for the exhaust gas temperature.

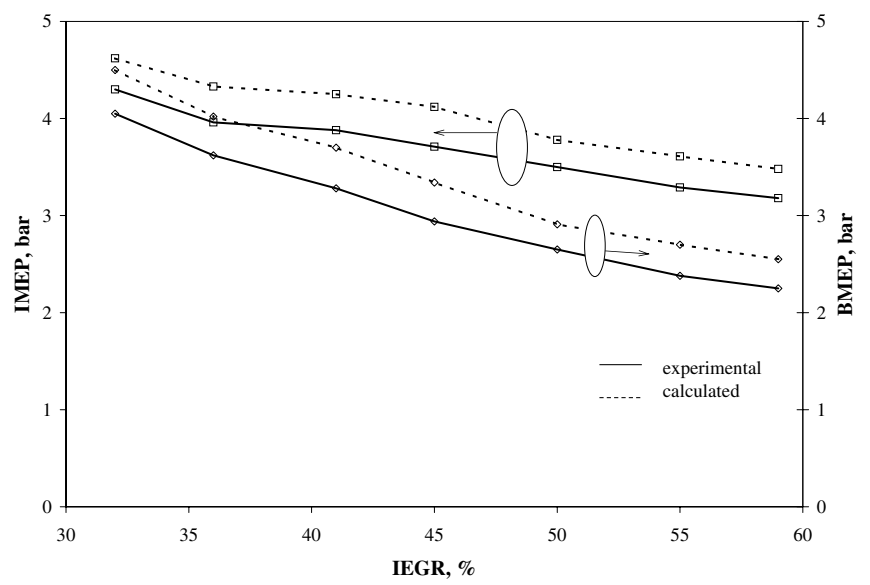

Figure 6: Comparison of calculated and experimental values or IMEP and BMEP.

are matched with good agreement and that values of $\mathrm{T}_{\text {exh }}$, IMEP, BMEP and BSFC are predicted within difference of $10 \%$. The differences are consistent with the results obtain for $50 \%$ TRG.

It is worth noting that with the use of LES code (in a combination with the Aurora detail chemical kinetics code ) for the modelling of the exhaust and induction process, the charge properties at IVC can be automatically calculated and used as an input to the Aurora code. This is very useful because the amount of trapped RG for a camless HCCI engine is not exactly known ${ }^{7}$. On the other hand, limitation of using this combined code is in an inability to predict correctly emissions of UHC and CO. These emissions strongly depend on a mixing process and a fuel captured in crevices and piston rings. To correct simulate emissions of UHC and CO emission it is necessary to have sufficient temporal and spatial resolution to resolve mixing and boundary layer effect.

It should be mentioned that accuracy of the model with unsymmetrical valve timings has exactly not known, since there were no available experimental data for its validation (experiments has not been performed with unsymmetrical EVC and IVO timings). Additional test with unsymmetrical valve timings and at other engine speeds (1000 rpm, $3000 \mathrm{rpm}$,

\footnotetext{
${ }^{7}$ The amount of trapped exhaust gas is an instantaneous value.
} 


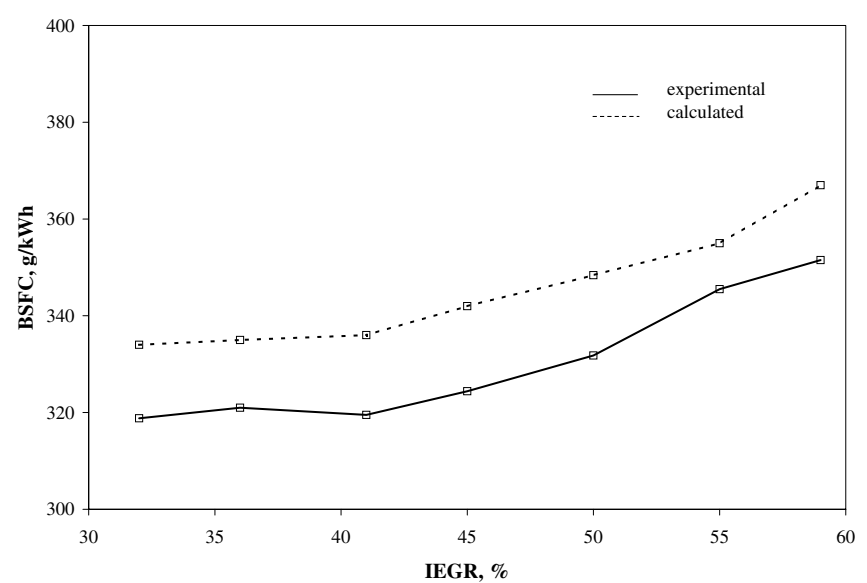

Figure 7: Comparison of calculated and experimental values for BSFC.

4000rpm and 5000rpm) are underway, and the data obtained from those tests will be used to re-validate the model and results will be published elsewhere.

\section{EXPERIMENTAL RESULTS}

Figure 8 shows the measured cylinder pressure histories for different quantities of TRG obtained by increasing the negative valve overlap. The test conditions were those summarised in Table 1 (Refer to Appendix).

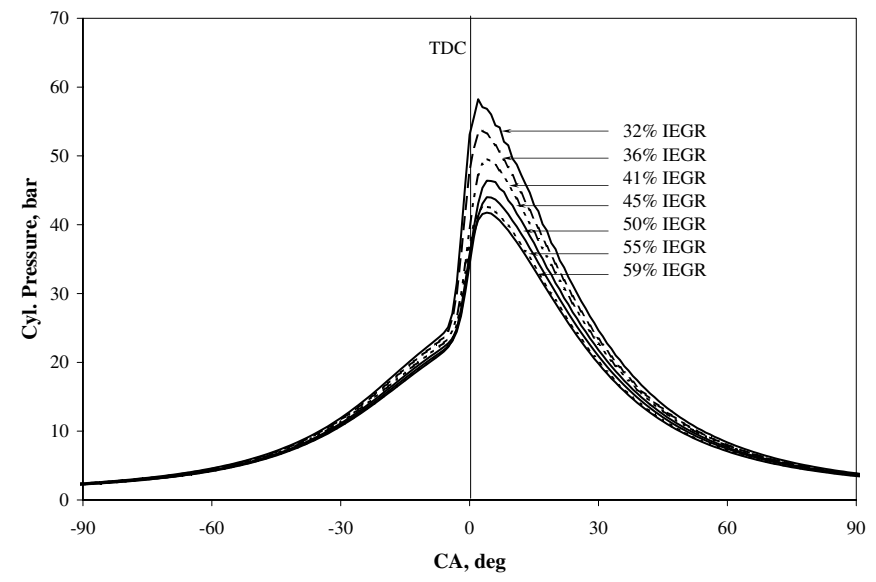

Figure 8: Experimental cylinder pressure curves for various amounts of TRG obtained by increasing the negative valve overlap.

It can be seen that the HCCI operation mode is achieved at $32 \%$ TRG and it is maintained to $59 \%$ TRG. For the values higher than $59 \%$ TRG the engine is not operated due to a very low load output, which is inappropriate for the practical application.

For TRG quantities below $32 \%$, the HCCI combustion cannot be generated and self-sustained, and it is necessary to use the spark-plug. The region below $32 \% \mathrm{TRG}$ is not the 'pure' HCCI operational mode, but neither is it the 'pure' SI mode, since the spark is only used to ignite the charge mixture and the turbulent flame propagation in the rest of unburned mixture is not observed. Instead of this, the unburned mixture is auto-ignited and sustained combustion in uniform and simultaneous auto-ignition process, as in the HCCI combustion. It is highly likely that this behaviour is achieved because the charge mixture is diluted by the TRG to such an extent that the temperature rise due to the spark ignited combustion is high enough to trigger auto-ignition in the unburned mixture.

This result indicates that the activation (energy) from the spark plug is not used as an essential combustion source like in the SI combustion strategy, but only as an assistance to the auto-ignition.

Even though the region below $32 \%$ TRG is not a 'pure' HCCI operational mode it is very interesting for an investigation, since it represents the transient mode between the SI and HCCI mode. Therefore, it can provide valuable information about the influence of variable valve timing strategy on the charge properties hence the potential to obtain control for transient operation. The importance of this region have been discussed in $[10,18,21,22]$.

It can be seen in Figure 8 that with a higher amount of TRG the peak cylinder pressure is reduced which is due to influence of the TRG chemical effect, as discussed in [19]. Chemical effect of TRG consists of several different effects which take place simultaneously: changing of the charge mixture heat capacity, dilution of the charge mixture, increasing the concentration of some exhaust gas species and influencing the radicals' production and destruction reactions ${ }^{8}$.

Ignition timing is not significantly affected with the increase of the TRG amount, as can be seen in Figure 9. With the highest amount of TRG (59\% TRG) the ignition timing is advanced only by $2^{0} \mathrm{CA}$ compared to the $32 \% \mathrm{TRG}$. The data for the ignition timing is obtained using ACAP data acquisition system from DSP Technologies. The start of ignition is assumed at the point where the cylinder pressure rise deviates from an isentropic or motored cylinder pressure trace. For each point where the HCCI operational mode is achieved $(32,36,41,45,55$ and $59 \%$ TRG) an isentropic pressure trace is produced from 'DSP datasum report'. Then a fit curve that matches the compression slope and the pumping loop is produced. The point of the cylinder volume where the isentropic curve deviates from the pumping loop (converted to a CA) is used as the start of ignition.

On the other hand, the combustion duration is considerably affected with the increase of the TRG amount (Refer to Figure 10). The combustion duration is defined as the crank angle interval the engine takes to complete 5 to $95 \%$ of heat release ${ }^{9}$.

It can be seen that with higher quantities of TRG the combustion duration becomes longer as a result of the reduced overall speed of combustion. With trapping RG, the amount of fuel in the resulting charge becomes lower and charge heat capacity becomes higher, which results in a less intense rate of energy release and reduced combustion temperature respectively and hence slows down the combustion rate.

\footnotetext{
${ }^{8}$ This division may be arguable. Some authors $[23,24]$ claimed that there are five different effects of TRG: thermal, heat capacity, dilution, the effect of increasing $\mathrm{H}_{2} \mathrm{O}$ and $\mathrm{CO}_{2}$ concentration and the effect of TRG constituents on some reactions.

${ }^{9}$ Combustion duration may also be defined as the crank angle interval the engine takes to complete 10 to $90 \%$ or to complete 15 to $85 \%$ of heat release [11].
} 


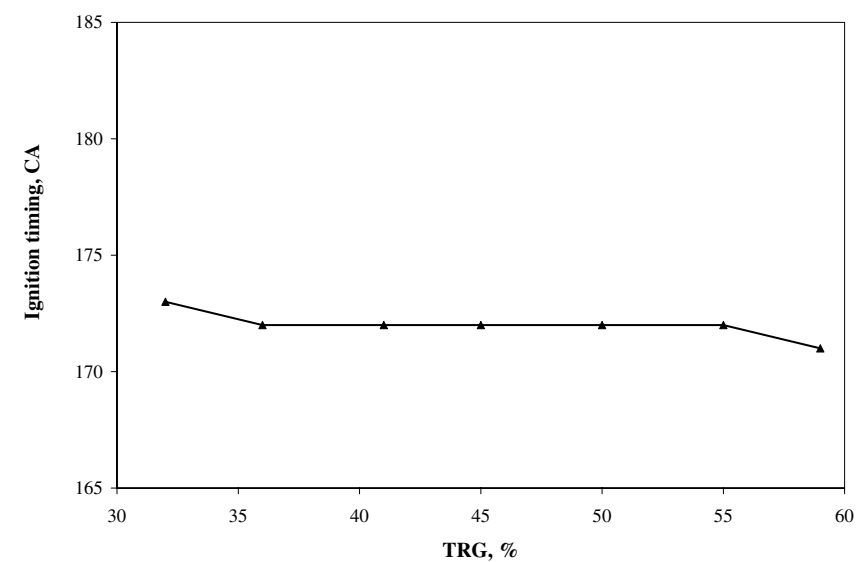

Figure 9: Ignition timing as a function of different amounts of TRG.

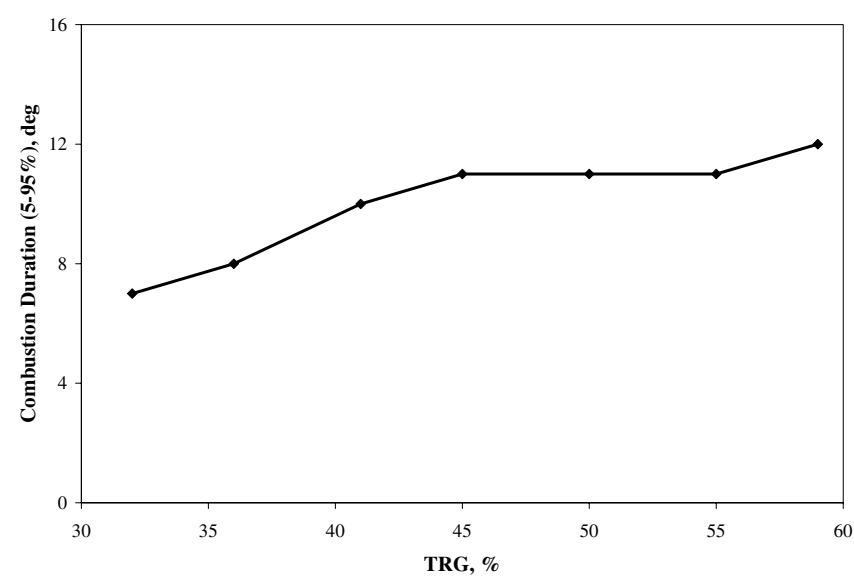

Figure 10: Combustion duration (5-95\%) as a function of different amounts of TRG.

The Texh,IMEP, BMEP and BSFC are also appreciable affected by the increase in the amount of trapped TRG, as can be seen in Figures 5, 6 and 7, respectively. With the increase in the amount of trapped TRG, the IMEP, BMEP, Texh decrease while BSFC increase. When a higher value of TRG is trapped, the amount of fresh air-fuel charge is reduced which results in lower load output-lower IMEP and also in lower generated torque-lower BMEP. Consequently, the engine at lower power gives reduced Texh. The fuel consumption increases with the higher amount of TRG (with the decrease in the load), mainly due to lower thermal efficiency and a high compression of the trapped RG that leads to high heat losses.

\section{SIMULATION RESULTS}

ANALYSED VALVE TIMING RANGE - The analysis of the influence of variable valve timings strategy on the gas exchange process and consequently on the engine parameters (such as trapped gas temperature, TRG amount, load, pumping losses, volumetric efficiency), and charge mixture properties (composition, temperature and pressure) is carried out by the LES code. The EVC from $235^{\circ} \mathrm{CA}$ to 375 ${ }^{0} \mathrm{CA}$ is investigated (Refer to Figure 11). The IVO is varied symmetrically relative to $\mathrm{TDC}_{\text {overlap }}$.

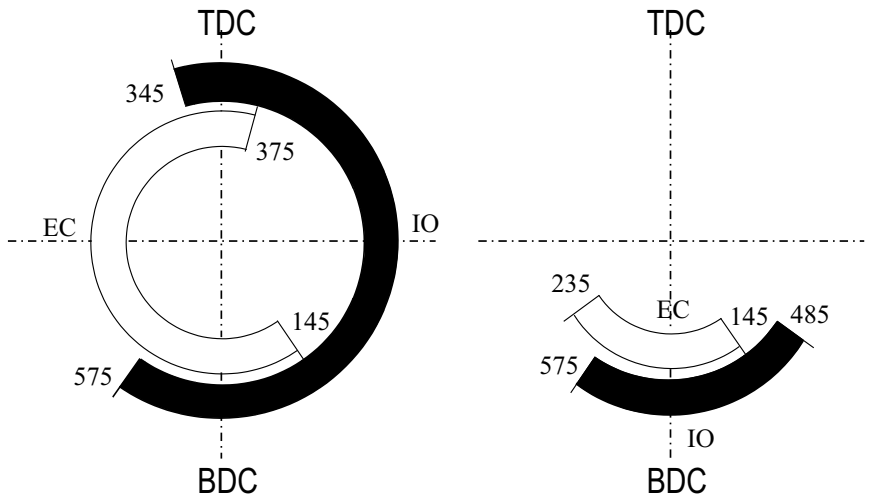

Figure 11: Analysed valve timings range from the positive to the negative valve overlap (in ${ }^{0} \mathrm{CA}$ ).

The EVO and IVC are kept constant at $145^{\circ} \mathrm{CA}$ and $575^{\circ}$ $\mathrm{CA}$ respectively.

The other engine parameters, such as the compression ratio, engine speed, intake temperature and equivalence fuel-air ratio are kept constant at values specified in Table 1 (Refer to Appendix).

INFLUENCE OF EVC AND IVO VALVE TIMINGS ON ENGINE PARAMETERS - The gas exchange process determines the quantity of TRG which in turn affects the combustion process and engine performance. The quantity of TRG influences the charge mixture temperature at the end of the intake stroke (IVC point) and therefore the ignition timing and heat release rate. Also, the quantity of TRG determines the amount of the fresh charge and therefore affects the engine's volumetric efficiency and load.

The changes in TRG quantity with the variations in EVC and IVO are shown in Figure 12, the changes in IMEP in Figure 13 and the changes in volumetric efficiency in Figure 14.

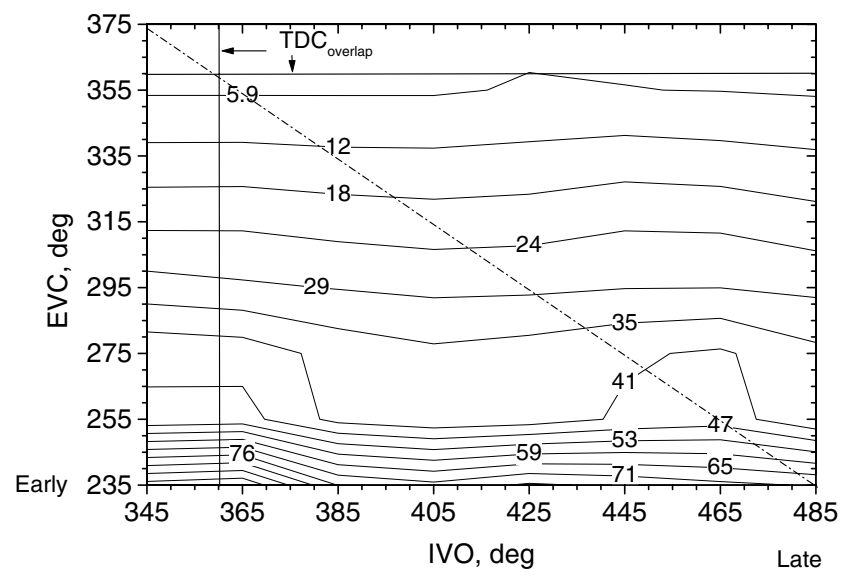

Figure 12: The TRG quantity as a function of EVC and IVO.

It can be seen that the TRG quantity, IMEP and volumetric efficiency are mainly influenced by the EVC. The TRG decreases with the later EVC, because less exhaust gases are 


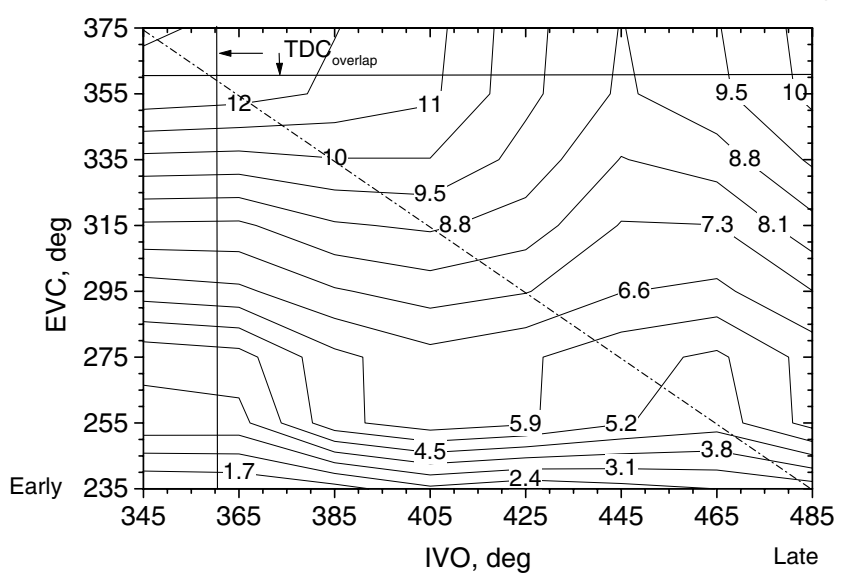

Figure 13: The IMEP as a function of EVC and IVO.

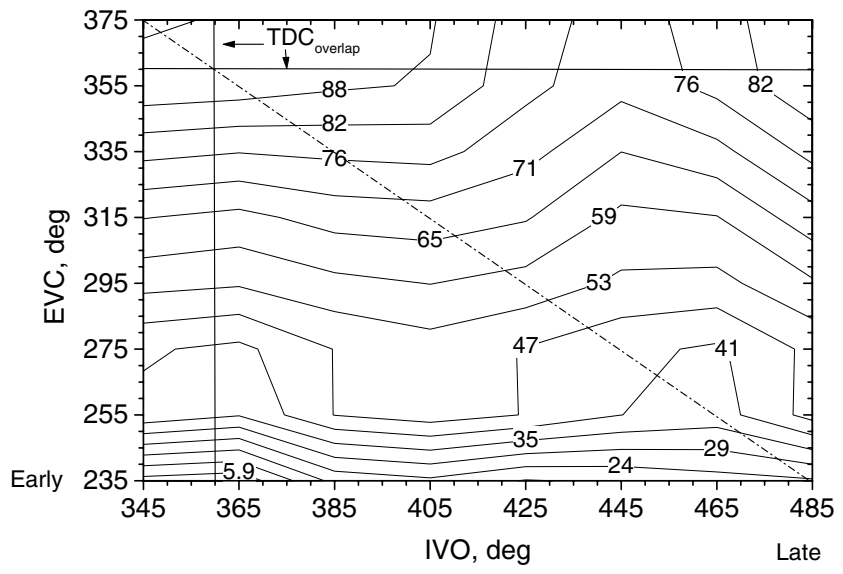

Figure 14: The Volumetric Efficiency as a function of EVC and IVO.

trapped. Therefore, the more fresh charge is introduced, resulting in an increase in volumetric efficiency and IMEP.

Overall, the IVO has considerably less influence on the TRG quantity, volumetric efficiency and IMEP, except in the two isolated regions ( 'islands'). These two 'islands' are for a very late IVO (from 445 to $485^{\circ} \mathrm{CA}$ ) and for a relatively early IVO (from 355 to $380^{\circ} \mathrm{CA}$ ), while the EVC range is from 250 to $275^{\circ} \mathrm{CA}$. A very late IVO causes the trapped exhaust gas to expand to the pressure below the inlet manifold pressure which affects the TRG quantity and IMEP. With a relatively early IVO, the cylinder pressure is above the intake manifold pressure which causes a reverse flow (at the intake valve) and therefore influences the TRG quantity and IMEP.

Influence of the EVC and IVO timing on the engine pumping losses is shown in Figure 15. The pumping losses are evaluated from the IMEP for the exhaust and intake strokes.

It can be seen that the minimum pumping losses take place for the symmetrical IVO. When the IVO is opened symmetrically, the in-cylinder pressure is near or equal to the intake manifold pressure and the minimum pumping losses occur. For a given IVO, the IVO required for a minimum pumping loss can be found from the dashed line in Figure 15.

A late IVO causes the trapped exhaust gas to expand to the pressure below the intake manifold pressure, as can be seen in Figure 16, which increases the pumping losses. On the

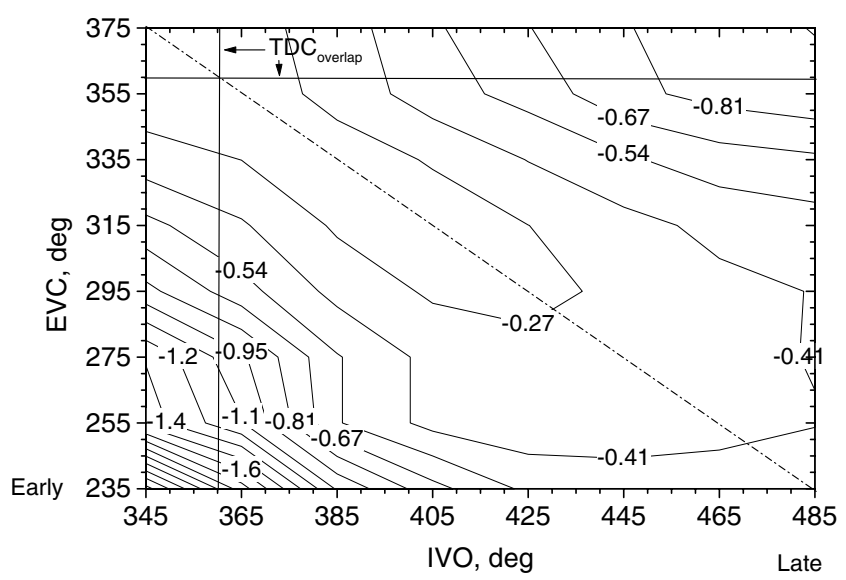

Figure 15: Pumping losses as a function of EVC and IVO.

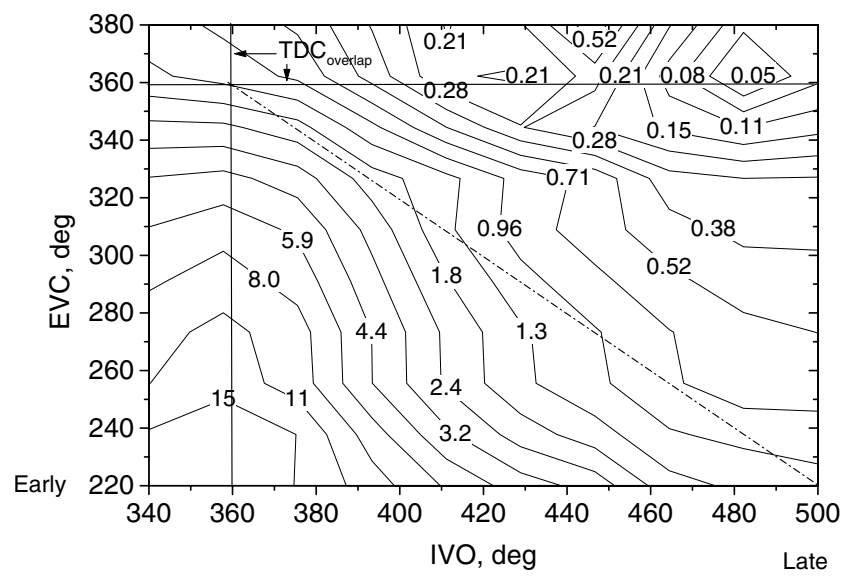

Figure 16: Cylinder pressure values at the IVO point as a function of EVC and IVO

other hand with an early IVO, the cylinder pressure is above the intake manifold pressure which causes reverse flow at the intake valve and thus an increase in the pumping losses.

From the experiments performed on the single-cylinder engine and conditions specified in Table 1 it is found that the HCCI combustion can be generated and self-sustained only for the quantities of TRG above $32 \%$. For an TRG quantity below this value the HCCI combustion cannot be generated and self-sustained without the use of a spark-plug (transient mode). The maximum quantity of TRG is constrained by the engine design to the $80 \%$ TRG.

Taking into account the importance of the transient mode and limitations of the engine design, the region from $23 \%$ TRG (transient mode) to $80 \%$ TRG is chosen for the investigation of the influence of EVC and IVO on the charge properties in engine manifolds. It can be seen in Figure 12 that this range of TRG is obtained for the EVC from 235 to $315^{\circ} \mathrm{CA}$ and the symmetrical IVO from 405 to $485^{\circ} \mathrm{CA}$ (with the step of $5^{0} \mathrm{CA}$ ).

\section{INFLUENCE OF THE EVC AND IVO VALVE TIMINGS ON CHARGE MIXTURE PROPERTIES}

Influence on the temperature at the EVC point - The effect of the EVC and IVO on the TRG temperature at the EVC point is shown in Figure 17. 


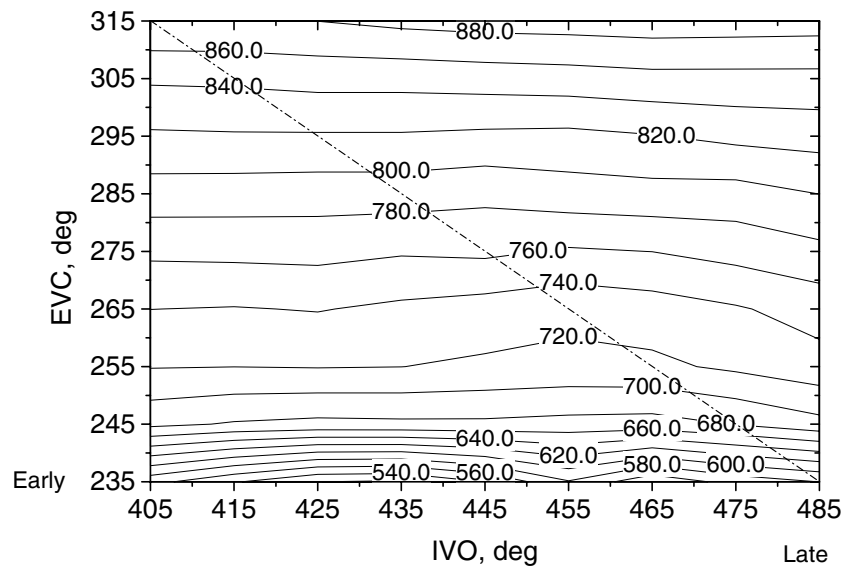

Figure 17: TRG temperature at the EVC point as a function of the EVC and IVO (in K).

It can be seen that the temperature at EVC is solely a function of the EVC, it decreases with the earlier EVC and thus with the higher TRG quantity (Refer to Figure 12). This behaviour is likely influenced by the boundary conditions at the EVO point, the pressure changes caused by the piston movement and indirectly by the valve movement, the compression heating and the TRG amount.

With the earlier EVC the amount of compression heating decreases which in conjunction with the higher TRG amount alters the rate of heat release and thus the temperature rise. This result is consistent with experimental results, i.e. the temperature of the exhaust gas (measured in the exhaust manifold) decreases with the earlier EVC-the increase in the amount of TRG (Refer to Figure 5). Similar observations have been reported from other experiments [25, 26].

Influence on the temperature at the $\mathrm{TDC}_{\text {overlap }}$ point The changes in the TRG temperature at the $\mathrm{TDC}_{\text {overlap }}$ point as the result of the EVC and IVO are shown in Figure 18.

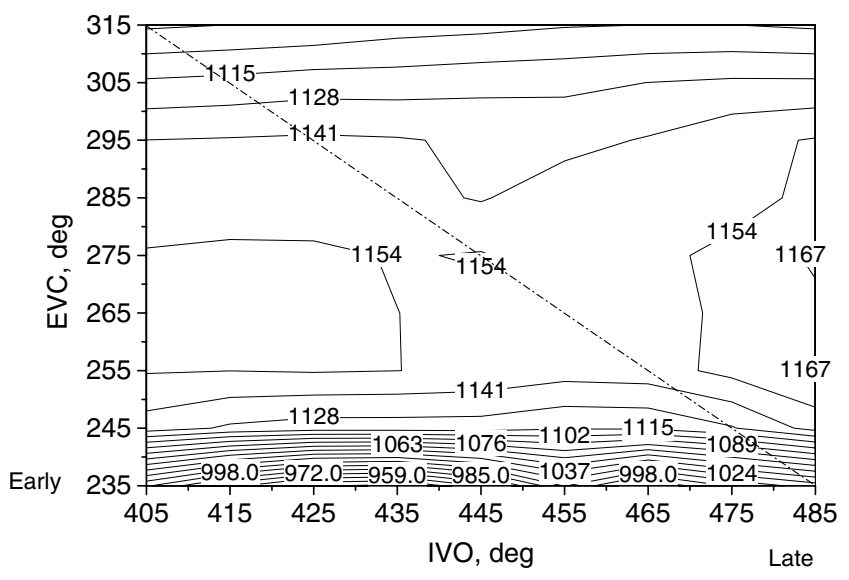

Figure 18: TRG temperature at the $\mathrm{TDC}_{\text {overlap }}$ point as a function of the EVC and IVO (in K).
It can be seen that the temperature is a primary function of the EVC with a negligible influence from the IVO. However, the IVO has a strong influence in two narrow regions, the region of a very early IVO (from 405 to $415^{\circ} \mathrm{CA}$, EVC from 255 to $275^{\circ} \mathrm{CA}$ ) and in the region of a relatively late IVO (from 455 to $450^{\circ} \mathrm{CA}, \mathrm{EVC}$ from 255 to $275^{\circ} \mathrm{CA}$ ). In these two regions the IVO influences the TRG temperature by the existence of a reverse flow, as discussed in Section .

It can be noted that for a very high TRG quantities-a very early EVC (from $235^{0}$ to $245^{\circ} \mathrm{CA}$ ), the temperature decreases since the temperature rise from the compression heating is reduced (by the presence of the high amount of inert gases in TRG). As the TRG quantity decreases, the temperature gain becomes higher resulting in the temperature increase (region from EVC $245^{\circ}$ to $285^{\circ} \mathrm{CA}$ ). For the further decrease in TRG quantity (region from EVC $290^{\circ}$ to $315^{\circ} \mathrm{CA}$ ), the temperature starts to decrease again. This is due to a lower charge heating caused by the shorter compression duration (compression of the TRG in the exhaust stroke). With the later occurrence of $\mathrm{EVC}$, the distance to $\mathrm{TDC}_{\text {overlap }}$ is reduced which leads to the shorter compression duration.

Therefore, the temperature rise during the compression of TRG in the exhaust stroke is the combined effect of two factors: (i) the TRG quantity and (ii) the amount of compression heating.

It is worth to note that there is a region where the TRG temperature is above $1100 \mathrm{~K}$ (for EVC between $245^{\circ}$ and $315^{\circ}$ CA). In this region it is highly likely that a secondary combustion due to TRG will occur [16, 21, 27, 28]. This combustion might have a strong impact on the unburned hydrocarbons (UHC) in the TRG and fuel captured in crevices. However, with the LES code, modelling of the UHC and fuel captured in crevices cannot be performed in this stage, but improvements are due in course.

Influence on the temperature at the IVO point - At the IVO point the induction valve is opened and a fresh air-fuel charge is mixed with the hot compressed TRG. The changes in the TRG temperature at the IVO point as a function of the EVC and IVO is presented in Figure 19.

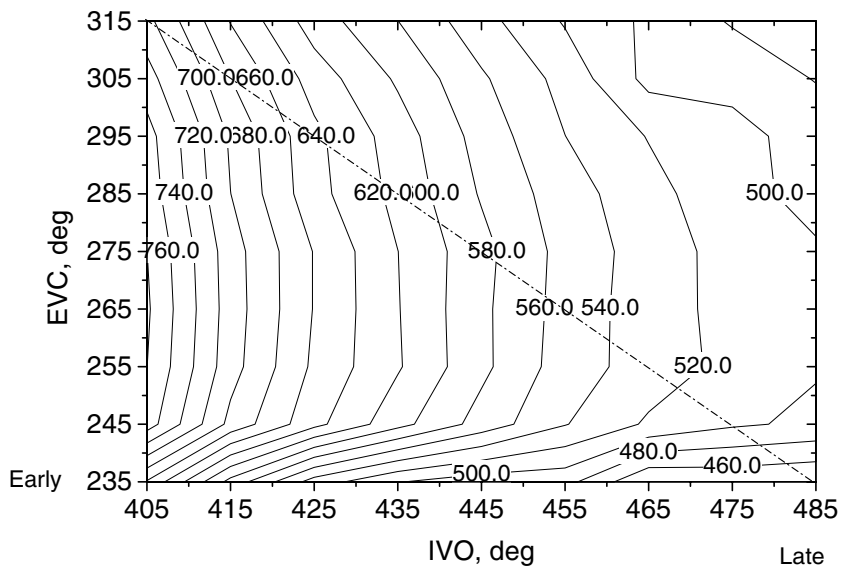

Figure 19: TRG temperature at the IVO point as a function of the EVC and IVO (in K). 
It can be seen that the temperature is mainly influenced by ${ }^{2}$ The highest temperature gradient in this region is mainly the IVO, it decreases with the later IVO. With the later IVO, the consequence of a significant temperature difference obthe cylinder volume increases causing a higher heat transfer loss which in turn reduces the TRG temperature and therefore decreases the charge mixture temperature.

However, there exists two regions where the charge mixture temperature is a function of both IVO and EVC timings:

i) The region for a very late IVO (from 475 to $485^{\circ} \mathrm{CA}$ ),

ii) The region for a very early EVC (from 235 to $245^{\circ} \mathrm{CA}$ ).

In these regions the temperature is influenced by the reverse TRG flow (caused by the IVO) and by a considerable quantity of the TRG (caused by the IVO).

Influence on the temperature at the IVC point - The effect of the EVC and IVO on the charge mixture temperature at the IVC point is shown in Figure 20.

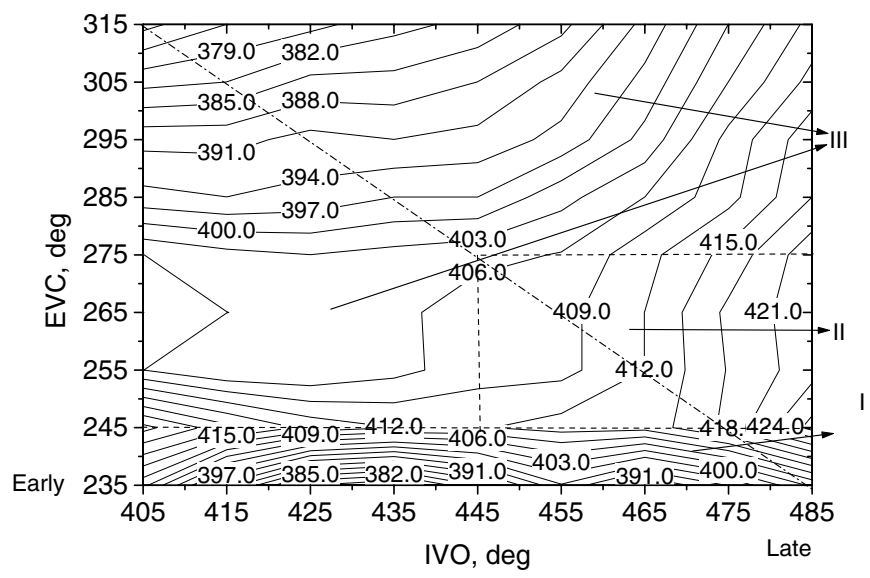

Figure 20: Charge mixture temperature at the IVC point as a function of the EVC and IVO (in K).

This temperature is closely related to the boundary conditions at the EVO point, the pressure changes caused by the piston movement and indirectly by the valve movement, the TRG quantity, the amount of compression during the exhaust stroke, the mixing of the TRG and fresh air-fuel charge (after IVO) and the intake air temperature. It can be seen that the temperature of the resulting charge mixture varies considerably (from 379 to $424 \mathrm{~K}$ ) and that three regions exist in which the temperature is determined only by the EVC or only by the IVO or by both timings.

In the first region, a very early EVC (from from $235^{\circ}$ to $245^{0} \mathrm{CA}$ ), the temperature is determined mainly by the EVC. This region is characterised by the highest charge mixture temperature $(424 \mathrm{~K})$ and the highest temperature gradient (from $424 \mathrm{~K}$ to $382 \mathrm{~K}$ ).

The highest mixture temperature achieved in this region $(424 \mathrm{~K})$ is due to the mixing of a large amount of hot TRG (about 70\%) with a small amount of cold fresh air-fuel charge. The charge mixture in this region has a high temperature combined with a high dilution which is very favourable for the HCCI combustion as discussed in $[17,21,25]$. It can be expected that this mixture will auto-ignite relatively early in the following cycle, producing a less intense heat release rate (longer combustion duration) and low peak cylinder pressure. This behaviour has been reported in $[21,25]$. tained during the exhaust stroke (during the compression of the TRG) and the existence of reverse flow (at the intake valve) at an asymmetrical IVO (Refer to Figure 18 and Figure 16 respectively).

Temperature in the second region (EVC from $245^{\circ}$ to $275^{\circ}$ $\mathrm{CA}$ and IVO from $445^{0}$ to $485^{\circ} \mathrm{CA}$ ), is primary influenced by the IVO. The temperature in this region changes from $421 \mathrm{~K}$ to $406 \mathrm{~K}$ which is considerably lower in comparison to the change in the first region. Also, it can be noticed that the temperature gradient in this region is considerably lower than that in the first region.

In the second region the TRG quantity is nearly constant $(\approx 40 \%)$ (Refer to Figure 12 ) and therefore the mixing and gas exchange processes are mainly determined by the amount of fresh charge, i.e. by IVO timing. A low variation in the charge mixture temperature is likely influenced by the IVO, i.e. by the non existence of the reverse flow (at the intake valve) at the beginning of the intake process and. The mixture in this region will be expected to auto-ignite later than the mixture in first region and to produce a higher heat release rate and peak cylinder pressure. This observation has been reported in $[21,25]$.

The rest of the map is the third region where the temperature is affected by both EVC and IVO. The temperature of resulting mixture in this region varies from $415 \mathrm{~K}$ to $379 \mathrm{~K}$ and it is determined by a relatively low amount of the hot TRG and a relatively high amount of the cold fresh air-fuel charge. The existence of a relatively high temperature gradient (from $415 \mathrm{~K}$ to $379 \mathrm{~K}$ ) for the EVC from $275^{0}$ to $315^{0}$ $\mathrm{CA}$ and the IVO from $405^{0}$ to $485^{\circ} \mathrm{CA}$, is mainly due to the influence of temperature variations in TRG (caused during the compression process of TRG in the exhaust stroke) and less due to the influence of reverse TRG flow (at the intake valve). On the other hand a relatively small temperature gradient (from $403 \mathrm{~K}$ to $379 \mathrm{~K}$ ) for the EVC from $245^{\circ}$ to $275^{\circ} \mathrm{CA}$ and the IVO from $405^{0}$ to $445^{\circ} \mathrm{CA}$, is probably due to the larger influence of the reverse flow than that of the temperature variations in TRG.

A relatively low mixture temperature and small TRG quantity in the third region, may cause mixture auto-ignition not to occur and require the spark-plug to be used to initiate the auto-ignition. The dilution of the resulting charge and the temperature rise from the spark-ignited combustion will be high enough to trigger the auto-ignition in the remaining unburned mixture and to sustain the HCCI combustion in the way explained in Section .

INFLUENCE OF THE EVO AND IVC VALVE TIMINGS ON ENGINE PARAMETERS AND CHARGE PROPERTIES - From the test results obtained using the singlecylinder research engine equipped with the FVVT system (explained in Section ) and from the experiments performed by Koopmans, L. and Denbratt [10] it was found that EVO and IVC have minor influence on the gas exchange process in a HCCI engine. The EVO has the major influence on pressure waves generated by the blow down and displacement processes. This result is in agreement with the test results reported in [11]. Nevertheless the pressures waves may have an influence on the TRG quantity trapped at the EVC point, 
but this influence is negligible in comparison to the influence of the EVC and IVO [21].

The IVC has a very low impact on the engine parameters as it mainly influences the effective displacement volume and effective compression ratio. This result is also in agreement with the test results reported in [11].

It is worth mentioning that an investigation of a separate control of combustion timing and combustion rate and a control of engine load, to accommodate changes in fuel properties and intake conditions, is underway and obtained results will be published in future papers. Parallel with this investigation, there are ongoing activities on a building and establishing control of a multi cylinder 'hybrid' HCCI/SI engine (four cylinders) equipped with the FVVT timing and a discussion about that engine will also be presented in future papers.

\section{CONCLUSIONS}

The influence of the variable valve timing strategy on the control of a HCCI engine fuelled with standard gasoline fuel (95RON) was analysed. The analysis was performed by the experimental and modelling approach. The single-cylinder research engine equipped with the fully variable valve train (FVVT) system was used for the experimental study. A combined code consisting of a detailed chemical kinetics code and one-dimensional fluid dynamics code was used for the modelling study.

The results obtained indicate that the variable valve timing strategy has a strong influence on the gas exchange process, which in turn has a significant effect on the control of engine parameters and charge properties. The EVC has the strongest influence followed by the IVO, whilst EVO and IVC have the minor influence.

The EVO primary determines the TRG quantity and consequently the amount of fresh charge and therefore influences the engine load, indicated power and volumetric efficiency. Furthermore, the TRG quantity (the EVC), affects the charge mixture composition, temperature and pressure at the IVC point, therefore the auto-ignition timing and further combustion process, hence the control of the HCCI combustion.

Influence of the IVO on engine parameters and control of the HCCI combustion is less pronounce. The IVO mainly influence the pumping losses and reverse flow of the TRG at the intake valve.

The influence of EVO and IVC on the engine parameters and charge mixture properties is negligible.

It can be concluded that the use of the variable valve timing strategy has the potential to control the engine parameters and charge properties at the IVC point, hence HCCI combustion.

Parallel with the gas exchange process, the mixing process that takes place between the IVO event and the IVC event, may influences the engine parameters and charge properties. The mixing process will be studied in a future research and the results will be published elsewhere.

\section{References}

[1] Onishi S., Jo S.H., Shoda K., Jo P.D., and S. Kato. Thermo -Atmosphere Combustion (ATAC) - A new Combustion Process for Internal Combustion Engines. SAE Paper 790501, 1979.

[2] Hultqvist A., Engdar U., Johansson B., and Klingmann J. Reacting Boundary Layers in Homogenous Charge Compression Ignition (HCCI) Engine. SAE Paper 200101-1032, 2001.

[3] Hultqvist A., Christensen M., Johansson B., Richter M., Nygren J., Hult J., and M. Alden. The HCCI Combustion Process in a Single Cycle-High Fuel Tracer LIF and Chemiluminescence Imaging. SAE Paper 2002-01-0424, 2002 .

[4] Christensen M., Johansson B., and Hultqvist. The Effect of Combustion Chamber Geometry on HCCI Operation. SAE Paper 2002-01-0425, 2002.

[5] Sjöberg M., Edling L.O., Eliassen T., Magnusson L., and Ångström H.E. GDI HCCI: Effects of Injection Timing and Air Swirl on Fuel Stratification, Combustion and Emission Formation. SAE Paper 2002-01-0106, 2002.

[6] Noguchi M., Y. Tanaka, Tanaka T., and Y. Takeuchi. A Study on Gasoline Engine Combustion by Observation of Intermediate Reactive Products During Combustion. SAE Paper 790840, 1979.

[7] Milovanovic N. and Chen R. A Review of Experimental and Simulation Studies on Controlled Auto-Ignition Combustion. SAE Paper 2001-01-1890, 2001.

[8] Law D., Kemp D., Allen J., Kirkpartick G., and Copland T. Controlled Combustion in an IC-Engine with a Fully Variable Valve Train. SAE Paper 2000-01-0251, 2000.

[9] Turner J., Blundell D., Bassett M., Pearson R., and R. Chen. The Impact on Engine Performance of Controlled Auto Ignition Versus Spark Ignition with Two Methods of Load Control. In Proceedings of GPC 2002 Global Powertrain Congress, Michigan, USA, September 2002.

[10] Koopmans L. and Denbratt I. A Four Stroke Camless Engine, Operated in Homogeneous Charge Compression Ignition Mode with Commercial Gasoline. SAE Paper 2001-01-3610, 2001.

[11] Heywood J.B. Internal Combustion Engine Fundamentals. McGraw-Hill Book Company, 1988.

[12] Kee R.J., Rupley F.M., Meeks E., and Miller J.A. CHEMKIN III: A Fortran Chemical Kinetics Package for the Analysis of Gas-Phase Chemical and Plasma Kinetics. Report SAND96-8216, Sandia National Laboratories, Livermore, CA, USA, 1996.

[13] Group of Authors. Lotus Engine Simulation (LES) Code Manual. Published by Lotus Cars Company Ltd., 2001. Hethel, Norfolk, UK.

[14] Woschini G. Universally Applicable Equation for the Instantaneous Heat Transfer Coefficient in the Internal Combustion Engine. SAE Paper 670931, 1967. 
[15] Ogink R. and Golovitchev V. Gasolline HCCI Modeling:Computer Program Combining Detailed Chemistry and Gas Exchange Process. SAE Paper 2001-01-3614, 2001.

[16] Westbrook C. Chemical Kinetics of Hydrocarbon Ignition in Practical Combustion Systems. In Proceedings of $28^{\text {th }}$ Combustion Symposium, Pleneary Lecture, Edinburgh, Scotland, UK, July 2000.

[17] Chen R., Milovanovic N., and Law D. A Computational Study on the Ignition Timing of HCCI Combustion in IC Engine Fuelled with Methane. In Proceeding of 2002 Spring Technical Metting of the Combustion Institute, Canadian Section, number Paper No. 53, pages 158-163, Windsor, Canada, May 2001. Canadian Section of The Combustion Institute.

[18] Chen R., Milovanovic N., Turner J., and Blundell D. Thermal Effect of Internal Gas Recirculation on Controlled Auto Ignition. SAE Paper 2003-01-0750, 2003.

[19] Chen R. and Milovanovic N. A Computational Study Into the Effect of Exhaust Gas Recycling on Homogeneous Charge Compression Ignition Combustion in Internal Combustion Engine Fuelled With Methane. International Journal of Thermal Sciences, 41:805-813, 2002.

[20] Milovanovic N., Chen R., Law D., and Turner J. Homogeneous Charge Compression Ignition Combustion and Fuel Composition. In Proceeding of $1^{\text {tht }}$ Internal Combustion Engine Symposium, number 20026075, pages 361-364, Tokyo, Japan, October 2002. JSAE.

[21] Koopmans L., Backlund O., and Denbratt I. Cycle to Cycle Variations: Their Influence on Cycle Resolved Gas Temperature and Unburned Hydrocarbons from a Camless Gasoline Compression Ignition Engine. SAE Paper 2002-01-0110, 2002.

[22] Koopmans L., Ström H., Lundgren S., Backlund O., and Denbratt I. Demostrating a SI-HCCI-SI Mode Change on a Volvo 5-Cylinder Electronic Valve Control Engine. SAE Paper 2003-01-0753, 2003.

[23] Dec J. A Computational Study of the Effect of Low Fuel Loading and EGR on Heat Release Rates and Combustion Limits in HCCI Engines. SAE Paper 2002-01-1309, 2002 .

[24] Zhao H., Peng Z., Williams J., and Ladommatos N. Understanding the Effects of Recycled Burnt Gases on the Controlled Auto-ignition (CAI) Combustion in FourStroke Gasoline Engines. SAE Paper 2001-01-360\%, 2001 .

[25] Zhao H., Li J., Ma T., and Ladommatos N. Performace and Analysis of a 4-Stroke Multi-Cylinder Gasoline Engine with CAI Combustion. SAE Paper 2002-01-0420, 2002.

[26] Law D., Allen J., and Chen R. On the Mechanism of Controlled Auto Ignition. SAE Paper 2002-01-0421, 2002 .

[27] Dec J. and Sjöberg M. A Parametric Study of HCCI Combustion- the Sources of Emissions at Low Loads and the Effects of GDI Fuel Injection. SAE Paper 2003-010752, 2002.

[28] Hongming X., Hyiyu F., Williams H., and Shilling I. Modelling Study of Combustion and Gas Exchange in a HCCI (CAI) Engine. SAE Paper 2002-01-0114, 2002.

\section{CONTACT}

Dr Nebojsa Milovanovic

Lotus Engineering, Hethel, Norwich, Norfolk NR14 8EZ, UK

E-mail:nmilovanovic@lotuscars.co.uk

Jamie Turner

Lotus Engineering, Hethel, Norwich, Norfolk NR14 8EZ, UK Email:jturner@lotuscars.co.uk

Dr Rui Chen

Department of Aeronautical and Automotive Engineering, Loughborough University, Loughborough, LE11 3TU, UK E-mail:r.chen@lboro.ac.uk

\section{NOMENCLATURE}

\section{Symbols $\epsilon$ \\ $n$}

Abbrevations
ABDC
ATDC
ATDC $_{\text {overlap }}$

AVT

BDC

BMEP

BSFC

BTDC $_{\text {overlap }}$

CA

EVC

EVO

FVVT

GEP

IMEP

IVC

IVO

MOP

$\mathrm{RG}$

$\mathrm{RON}$

TDC

$\mathrm{TDC}_{c o m b}$

TRG
Compression ratio

Revolutions per minute $(1 / \mathrm{min})$

After bottom dead centre

After top dead centre

After top dead centre overlap

(gas exchange process)

Active valve train

Bottom dead centre

Break mean effective pressure

Break specific fuel consumption

Before top dead centre overlap

(gas exchange process)

Crank angle

Exhaust valve closure

Exhaust valve open

Fully variable valve train

Gas exchange process

Indicated mean effective pressure

Inlet valve closure

Inlet valve open

Maxim open point (valve)

Residual gases

Research octane number

Top dead centre

Top dead centre combustion

Trapped residual gases 


\section{APPENDIX}

Table 1: Single-cylinder engine specification and test conditions

\begin{tabular}{|c|c|}
\hline Bore & $80.5 \mathrm{~mm}$ \\
\hline Stroke & $88.2 \mathrm{~mm}$ \\
\hline Swept volume & $450 \mathrm{~cm}^{3}$ \\
\hline Compression Ratio & 10.5 \\
\hline Speed & up to $5000 \mathrm{rpm}$ \\
\hline Load Range & $2-5$ bar (IMEP) \\
\hline Number of valves per cylinder & 4 \\
\hline Valve Control & Electro-hydraulic \\
& Lotus AVT-FVVT system \\
\hline Fuel Injection & Port fuelled \\
\hline Fuel & Stoichiometric \\
\hline Equivalence air-fuel ratio & $25^{\circ} \mathrm{C}$ \\
\hline Intake Temperature & Naturally Aspirated \\
\hline Inlet Pressure & up to $80 \%$ (by volume) \\
\hline IEGR &
\end{tabular}

Table 2: Comparison of the calculated and experimental values for several engine parameters

\begin{tabular}{|c|c|c|c|}
\hline Engine Parameter & Calculated & Experimental & Difference (\%) \\
\hline \hline IMEP (bar) & 3.78 & 3.50 & +7.9 \\
\hline BMEP (bar) & 2.91 & 2.65 & +9.8 \\
\hline Indicated power (kW) & 2.73 & 2.63 & +3.8 \\
\hline Volumetric efficiency (\%) & 32.4 & 30.3 & +6.3 \\
\hline Mechanical Efficiency (\%) & 75.2 & 70.4 & +6.8 \\
\hline BSFC (g/kWh) & 348.4 & 331.8 & +5 \\
\hline Temp. in exhaust manifol. $\left({ }^{\circ} \mathrm{C}\right)$ & 457 & 452 & +1.1 \\
\hline Temp. at IC point (K) & 419 & & +3.8 \\
\hline IEGR (\%) & 52 & $50^{\star}$ & \\
\hline
\end{tabular}

